\title{
Developmental Regulation of Galactokinase in Suckling Mouse Liver by the Egr-1 Transcription Factor
}

\author{
FANG YANG, TAMAR AGULIAN, JASON E. SUDATI, DAVID B. RHOADS, AND \\ LYNNE L. LEVITSKY \\ Pediatric Endocrine Unit, MassGeneral Hospital for Children, Harvard Medical School, Boston, \\ Massachusetts, 02114, U.S.A. [F.Y., T.A., J.E.S., D.B.R., L.L.L.], and Harvard Medical School, Boston, \\ Massachusetts, 02115, U.S.A. [F.Y., D.B.R., L.L.L.]
}

\section{ABSTRACT}

The numerous changes in metabolic pathways that accompany liver development entail associated changes in gene expression. Egr-1 is a zinc-finger transcription factor that regulates genes involved in cellular growth, differentiation, stress response, and apoptosis in many cell types. Egr-1 is induced in liver regeneration in rodents, but its role in normal hepatocyte function has not been characterized. We examined the developmental expression of Egr-1 in mouse liver and found that its expression increased during the suckling period. In screening the sequences of the genes involved in lactose assimilation, we found that the galactokinase gene Glk contains four potential Egr-1 binding sites in its proximal promoter. A minimal promoter of 155 nucleotides encompassing the four Egr-1 sites exhibited activity in hepatoma cell lines by transient transfection assays. Moreover, co-transfection of an Egr-1 expression plasmid increased promoter activity. Finally, mutations introduced into three of the four Egr-1 binding sites decreased activity, whereas mutation of the remaining site increased promoter activity. These data tie Egr-1 and galactokinase together in a developmentally regulated chain to prepare the neonate for suckling. (Pediatr Res 55: 822-829, 2004)

Abbreviations
PRL-1, phosphatase of regenerating liver-1
PMSF, phenylmethylsulfonyl fluoride
PAP, potato acid phosphatase

action (12), and in monitoring food intake status by the CNS (13).

The Egr-1 gene encodes a transcription factor that contains three zinc fingers of the Cys2-His2 subtype $(14,15)$. The zinc fingers are located in the carboxy terminus and confer DNA binding function, whereas the transactivation domain is located in the amino terminus $(15,16)$. The three zinc fingers recognize the GC-rich consensus DNA sequence "GCG(G/T)GGGCG," with each finger spanning three nucleotides. Other studies have shown that variant sequences can mimic the consensus and also bind Egr-1 (17, 18). Egr-1 motifs have been found in the promoter regions of many genes. These genes include transcription factors, growth factors or their receptors, cell cycle regulators, hormones, and thymidine kinase (15).

Egr-1 binding activity was rapidly induced during the early phase of liver regeneration (19). Egr-1 has been found to up-regulate the expression of the phosphatase of regenerating liver-1 (PRL-1) gene, which may play an important role in cell growth via regulation of protein tyrosine phosphorylation and dephosphorylation. Because there was no obvious correlation between expression of Egr-1 and PRL-1 in other tissues (e.g. brain and muscle) or tumor cells (e.g. H35, HepG2, HeLa,
Received September 16, 2003; accepted December 8, 2003.

Correspondence: David B. Rhoads, Ph.D., Pediatric Endocrine Unit, MassGeneral Hospital for Children, 55 Fruit Street, BHX410, Boston, MA 02114-2696, U.S.A.; e-mail: drhoads@partners.org

Supported by U.S. Public Health Service Grants HD31215 (L.L.L.) and DK54399 (D.B.R.), and by March of Dimes Grant \#1-FY99-221 (D.B.R.).

DOI: 10.1203/01.PDR.0000120682.05408.79 
CV1), Egr-1 regulation of PRL-1 was assumed to be specific to regenerating liver (19). Activity of the Egr-1 promoter in liver has also been studied in transgenic mice (20), in which reporter gene expression was observed in hepatocytes and further induced after partial pancreatectomy.

We examined Egr-1 expression during development in the mouse. In mice, Egr-1 expression increased shortly after birth but decreased 3-4 wk later. Because the liver plays a central role in metabolic functions of the body and maximal Egr-1 expression occurred during suckling, we examined genes involved in the metabolism of lactose, the principal carbohydrate of milk. Lactose is initially hydrolyzed by $\beta$-galactosidase to glucose and galactose, which are absorbed into the bloodstream via intestinal sugar transporters. Once galactose reaches the liver, it is phosphorylated by galactokinase (E.C. 2.7.1.6) before conversion to glucose-6- $\mathrm{PO}_{4}$. Examination of the galactokinase gene promoter revealed the presence of several potential Egr-1 binding sites. Analysis of the galactokinase promoter in several hepatoma cell lines indicated that the potential Egr-1 binding sites in the galactokinase gene are functional and participate in galactokinase promoter activity. Moreover, mutants in Egr-1 binding elements decrease galactokinase promoter activity. Based on our studies, we conclude that Egr-1 is one of the transcription factors contributing to the developmental expression pattern of galactokinase in the mouse.

\section{MATERIALS AND METHODS}

$\boldsymbol{R N A}$ analysis. RNA extraction and blot analysis were performed as described previously (21) except that TRIzol LS Reagent (Invitrogen, Carlsbad, CA, U.S.A.) was used. Briefly, $20 \mu \mathrm{g}$ total RNA extracted from livers of mice killed at different ages were electrophoresed on a $1 \%$ agarose/ formaldehyde gel, transferred to a HyBond-N membrane (Amersham Biosciences, Piscataway, NJ, U.S.A.), hybridized with ${ }^{32} \mathrm{P}$-labeled DNA probes in Rapid-hyb Buffer (Amersham Biosciences) for $1-2 \mathrm{~h}$ at $65^{\circ} \mathrm{C}$, and washed. The hybridized blot was exposed to Kodak XAR5 BioMax film (Eastman Kodak, Rochester, NY, U.S.A.). Probes were labeled with $\left[\alpha-{ }^{32} \mathrm{P}\right] \mathrm{dCTP}$ (PerkinElmer Life Science, Boston, MA, U.S.A.) using the Megaprime DNA Labeling System (Amersham Biosciences). The following cDNA probes were used: mouse Egr-1, a 2.2-kb fragment from the 5' end; galactokinase, a $0.5-\mathrm{kb}$ PCR fragment within the coding region of the mouse transcript; the glyceraldehyde 3-phosphate dehydrogenase $(\mathrm{GAPDH})$ probe used previously (21); and the bacterial Gpt neomycin resistance gene, a $0.93 \mathrm{~kb}$ Pst I fragment excised from the retroviral vector pMV7neo.

Preparation of nuclear extracts and western blotting. Nuclear extracts of mouse liver were prepared according to a published procedure (22). All steps were performed at $0-4^{\circ} \mathrm{C}$. Liver tissues were disrupted by incubation in hypotonic buffer (10 mM NaHEPES, pH 7.9, $1.5 \mathrm{mM} \mathrm{MgCl}_{2}, 0.5 \mathrm{mM}$ spermidine, $1 \mathrm{mM}$ DTT, $1 \mathrm{mM}$ PMSF, and $1 \mu \mathrm{g} / \mathrm{mL}$ each of leupeptin, aprotinin, and antipain) for $10 \mathrm{~min}$ followed by Dounce homogenization. Tissue homogenates were filtered through cheesecloth. Released nuclei were sedimented at 800 $\times g$ for $5 \mathrm{~min}$, washed, and extracted in five volumes of hypertonic extraction buffer (30 mM NaHEPES, $\mathrm{pH} 7.9,25 \%$ glycerol, $450 \mathrm{mM} \mathrm{NaCl}, 0.3 \mathrm{mM}$ EDTA, $12 \mathrm{mM} \mathrm{MgCl}_{2}, 6 \mathrm{mM}$ DTT, plus protease inhibitors) for $45 \mathrm{~min}$. Extracts were centrifuged at $40,000 \times g$ for $30 \mathrm{~min}$ and the supernatant was dialyzed against extraction buffer containing $150 \mathrm{mM} \mathrm{NaCl}$ at least $3 \mathrm{~h}$, and stored in aliquots at $-80^{\circ} \mathrm{C}$. Protein concentration was determined using the Bio-Rad Protein Assay (Bio-Rad Laboratories, Hercules, CA, U.S.A.). Nuclear extracts were electrophoresed on a $12 \%$ SDS-PAGE gel and trans-blotted to a PVDF-Plus membrane (Osmonics, Inc., Minnetonka, MN, U.S.A.). Anti-mouse Egr-1 antibody was provided by J. Milbrandt (Washington University School of Medicine, St. Louis, $\mathrm{MO}$ ). Bound immune complexes were detected using enhanced chemiluminescence (Amersham Biosciences).

Electrophoretic mobility shift assay (EMSA). The sense sequence of the consensus Egr-1 binding site is GGATCCAGCGGGGGCGAGCGGGGGCGA. Annealed sense and antisense oligonucleotides were end labeled with T4 polynucleotide kinase (New England BioLabs, Beverly, MA, U.S.A.) and $\left[\gamma_{-}{ }^{32} \mathrm{P}\right] \mathrm{ATP}$ and purified by MicroSpin G-25 column (Amersham Biosciences). Nuclear extracts $(4 \mu \mathrm{g})$ were incubated with $1 \mu \mathrm{g}$ poly $(\mathrm{dI}-\mathrm{dC})$ in $10 \mu \mathrm{L}$ binding buffer containing $10 \mathrm{mM}$ HEPES, $\mathrm{pH} 7.9,100 \mathrm{mM} \mathrm{KCl}, 5 \mathrm{mM} \mathrm{MgCl} 2,0.5$ $\mathrm{mM}$ EDTA, $6 \mathrm{mM}$ DTT, and 5\% glycerol on ice. For super shift, $1 \mu \mathrm{L}$ of antibody was added to the reaction on ice for 20 min. For treatment with PAP (Sigma Chemical), $80 \mathrm{ng}$ was added to the extract for $10 \mathrm{~min}$ at $37^{\circ} \mathrm{C}$ and $10 \mathrm{mM} \mathrm{NaMoO}$ was included in the binding buffer. For competition with cold probe, $100 \mathrm{ng}$ unlabeled probe was added before addition of the labeled probe, and incubated for another $20 \mathrm{~min}$ at room temperature. DNA-protein complexes were electrophoresed at $100 \mathrm{~V}$ in $0.5 \times \mathrm{TGE} / 4 \%$ polyacrylamide gels at $4^{\circ} \mathrm{C}(1 \times \mathrm{TGE}$ is $50 \mathrm{mM}$ Tris, $380 \mathrm{mM}$ glycine, $1.0 \mathrm{mM}$ EDTA). Gels were dried and exposed to film overnight.

Cell culture and transfection analysis. Human hepatoma cell lines HepG2, Hep3B, and Huh7 were grown in six-well clusters in Dulbecco's modified Eagle's medium (DMEM, CellGro, Mediatech, Inc., Herndon, VA, U.S.A.) supplemented with $10 \%$ fetal bovine serum, 100 units of penicillin, and 50 units of streptomycin. Medium was changed every $72 \mathrm{~h}$. For transient transfection, cultures at $50 \%$ confluency were transfected with 1-2 $\mu \mathrm{g}$ DNA and $4 \mu \mathrm{L}$ Lipofectin Reagent (Invitrogen), following the supplier's protocol. Luciferase activity was measured by the Dual-Luciferase Reporter Assay System (Promega, Madison, WI, U.S.A.) using the Monolight 2010 Luminometer (BD Biosciences, Mississauga, ON, Canada). Renilla Luciferase (100 ng, Promega) was co-transfected with the experimental plasmids to normalize for transfection efficiency.

Plasmid construction and point mutations. Different fragment lengths of the galactokinase promoter were generated by PCR with gene-specific primers. Amplifications were performed in $10 \mu \mathrm{L}$ reaction containing DNA, $0.5 \mu \mathrm{M}$ primers, $0.2 \mathrm{mM}$ dNTP, $1 \mu \mathrm{L} 10 \times$ buffer, $4 \mathrm{mM} \mathrm{MgCl}_{2}$, and $0.6 \mathrm{U} \mathrm{Taq}$ Polymerase (Fisher BioTech, Pittsburgh, PA, U.S.A.) using a RapidCycler (Idaho Technology, Idaho Falls, ID, U.S.A.). Initially, GLKp-F and GLKp-R (see below) were used to amplify a 5 '-flanking gene fragment from mouse genomic 
DNA using the following steps: denaturation at $94^{\circ} \mathrm{C}$ for $15 \mathrm{~s}$; 38 cycles of denaturation at $94^{\circ} \mathrm{C}$ for $0 \mathrm{~s}$, annealing at $56^{\circ} \mathrm{C}$ for $0 \mathrm{~s}$, and elongation at $72^{\circ} \mathrm{C}$ for $10 \mathrm{~s}$; then extension at $72^{\circ} \mathrm{C}$ for 3 min. Ligation of this product between the NheI and HindIII sites of pGL3-basic firefly luciferase vector (Promega) yielded plasmid pGK $(-425)$ Luc containing the 425 nucleotides upstream of the ATG start codon. Shorter inserts were amplified from this PCR product using 30 cycles and the same reverse primer along with the additional nested forward primers shown below:

$$
\begin{array}{llr}
\text { GLKp-F } & \text { 5'-CTAGACTGTGTACCACATCAT } & \text { pGK(-425)Luc } \\
\text { GLKp-R } & \text { 5'-GCAAGCTTGACGCTCGTCTG } & \text { (Reverse) } \\
\text { GLKp-F6 } & \text { 5'-CGCTAGCCATTTGTGTTAAC } & \text { pGK(-272)Luc } \\
\text { GLKp-F7 } & \text { 5'-CGCTAGCTGGAGAGCTAAGTT } & \text { pGK(-155)Luc } \\
\text { GLKp-F8 } & \text { 5'-CGCTAGCGAAGGACAGGAAT } & \text { pGK(-83)Luc }
\end{array}
$$

Inserts were digested with NheI and HindIII and cloned into pGL3-basic. Thus, all promoters have the same proximal end and the numbering indicates the extent upstream.

Point mutations were introduced into pGK $(-155) \mathrm{Luc}$ and pGK $(-83)$ Luc by PCR with pairs of overlapping primers covering the site(s) to be mutated and containing the desired nucleotide changes. Separate reactions were used to amplify the upstream fragment with the "antisense" mutant primer and the respective forward primer for the fragment and the downstream fragment with the "sense" mutant primer and GLKp-R. The two reactions were combined and amplified an additional 10 cycles to generate full-length fragments. These were isolated by gel electrophoresis, digested with NheI and HindIII, and ligated into pGL3-basic. The primers were:

GLK(-155)mA-sense: ATGGGCGGGTTAGTCGTAGCGGGGGCGGGGT GLK(-155)mA-antisense: ACCCCGCCCCCGCTACGACTAACCCGCCCAT GLK(-155)mB-sense: ATGGGCGGGGCCGTCGTAGCGGGTTTGGGGT GLK(-155)mB-antisense: ACCCCAAACCCGCTACGACGGCCCCGCCCAT GLK(-155)mAB-sense: ATGGGCGGGTTAGTCGTAGCGGGTTTGGGGT GLK(-155)mAB-antisense: ACCCCAAACCCGCTACGACTAACCCGCCCAT GLK(-83)mA-sense: GCTCCTTACCCAGCATCCCGCGGGGCGGTGCG GLK(-83)mA-antisense: CGCACCGCCCCGCGGGATGCTGGGTAAGGAGC GLK(-83)mB-sense: GCTCCGCCCCCAGCATCCCGTTTGGCGGTGCG GLK(-83)mB-antisense: CGCACCGCCAAACGGGATGCTGGGGGCGGAGC GLK(-83)mAB-sense: GCTCCTTACCCAGCATCCCGTTTGGCGGTGCG GLK(-83)mAB-antisense: CGCACCGCCAAACGGGATGCTGGGTAAGGAGC

Fidelity of the PCR amplification was confirmed by sequencing before use of the constructs in transfections.

Immunohistochemistry. Liver pieces were formalin fixed and paraffin embedded. Sections $(5 \mu \mathrm{m})$ were immunostained with Egr-1 primary antibody and horseradish peroxidaseconjugated second antibody. Slides were developed with Vector $\mathrm{ABC}$ and DAB substrate (Urs Berger, Beth Israel Deaconess Medical Center In situ Hybridization Core Facility, Boston, MA, U.S.A.).

Statistics. Significance was taken to be the $95 \%$ confidence level using a two-sample $t$ test assuming unequal variances $(p<0.05)$.

Animals. All experiments with mice used in this study were approved by the Massachusetts General Hospital Subcommittee on Research Animal Care

\section{RESULTS}

Developmental expression of Egr-1 in mouse liver. To obtain a detailed picture of the changes in Egr-1 expression in mouse liver, we examined its expression at several developmental stages. When immunostaining was performed on mouse liver sections, uniform nuclear staining for Egr-1 was observed at postnatal d 3 (Fig. 1). The signal was clearly present in a majority of the hepatocytes. No Egr-1 protein was detected in liver sections from mice at postnatal d 1 (Fig. 1) or before (not shown). A strong signal for Egr-1 was found for up to 3-4 wk (Fig. 1), but was generally less or absent in older mice (not shown). These data indicate that Egr-1 exhibits a brief period of enhanced expression in mouse liver during the suckling phase.

The developmental changes in Egr-1 mRNA levels were examined by Northern blotting analysis. The hybridization signal revealed a complex pattern. Egr-1 mRNA levels increased markedly at birth and the robust expression persisted during the suckling period. Between 3 and 4 wk of age, the level decreased to the basal level characteristic of adult mice (Fig. 2A). The level of Egr-1 mRNA in adult mouse liver was lower than that found at embryonic d 18, the earliest time examined in this study. The Egr-1 protein was detectable in liver nuclear extracts by Western blotting up to $3 \mathrm{wk}$ of age (Fig. $2 B$ ) and was generally not detected afterward. As expected, no protein was present in extracts from Egr-1 null mice (Fig. 2B). These data indicate that the developmental surge in Egr-1 expression occurs at the level of mRNA. Whether the changes observed were due to alterations in transcription rate or in mRNA stability was not examined.

DNA binding was examined by electrophoretic mobility shift assay. Nuclear extracts prepared from mice at 1-2.5 wk of age formed a very strong complex with the Egr-1 probe (Fig. $2 C$ ). The complex was much weaker at 2 or $4 \mathrm{~d}$ and essentially
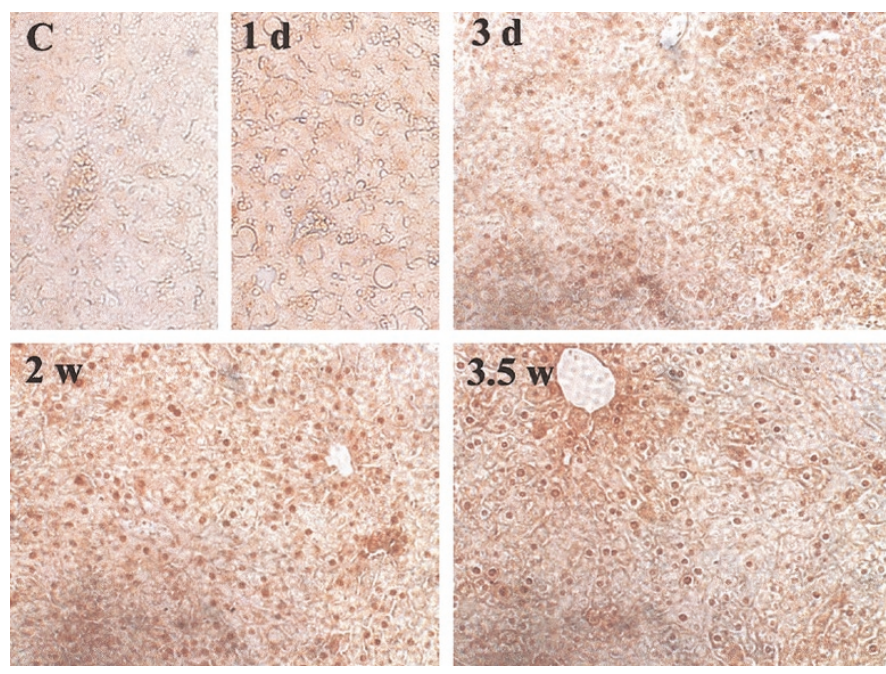

Figure 1. Egr-1 immunohistochemistry. Liver samples from mice of the indicated ages were immunostained with Egr-1 primary antibody and horseradish peroxidase-conjugated secondary antibody (Urs Berger, BIDMC In situ Hybridization Core Facility). Note the widespread distribution of positively stained hepatocyte nuclei from d 3 onward. Panel $C$ is a negative control in which a section from a 2 -wk-old mouse was stained with secondary antibody only. 


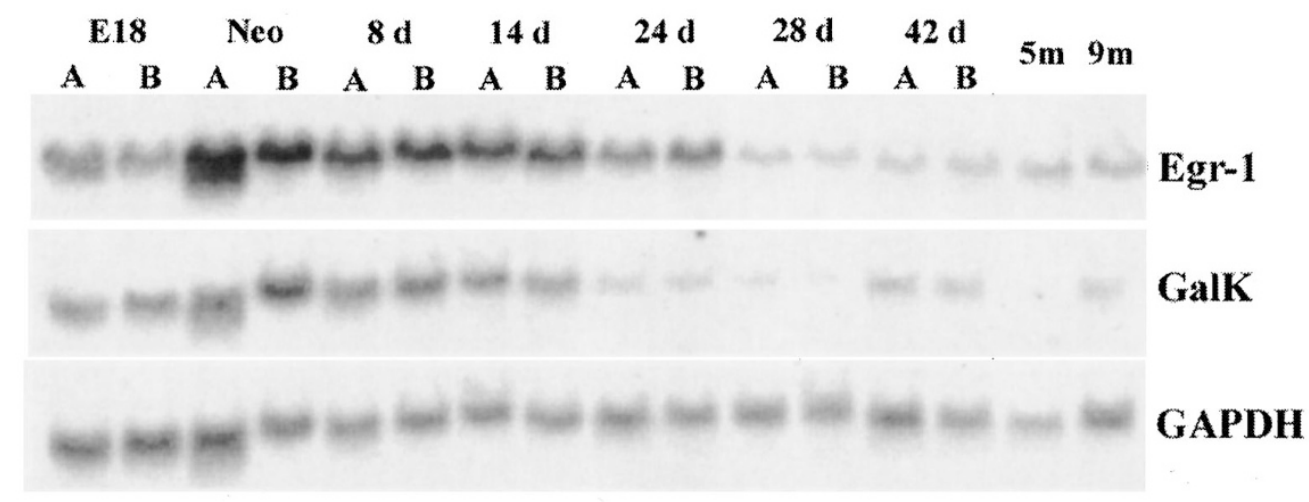

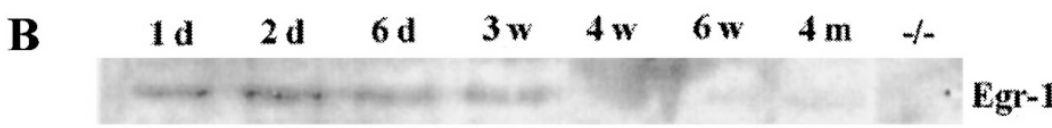
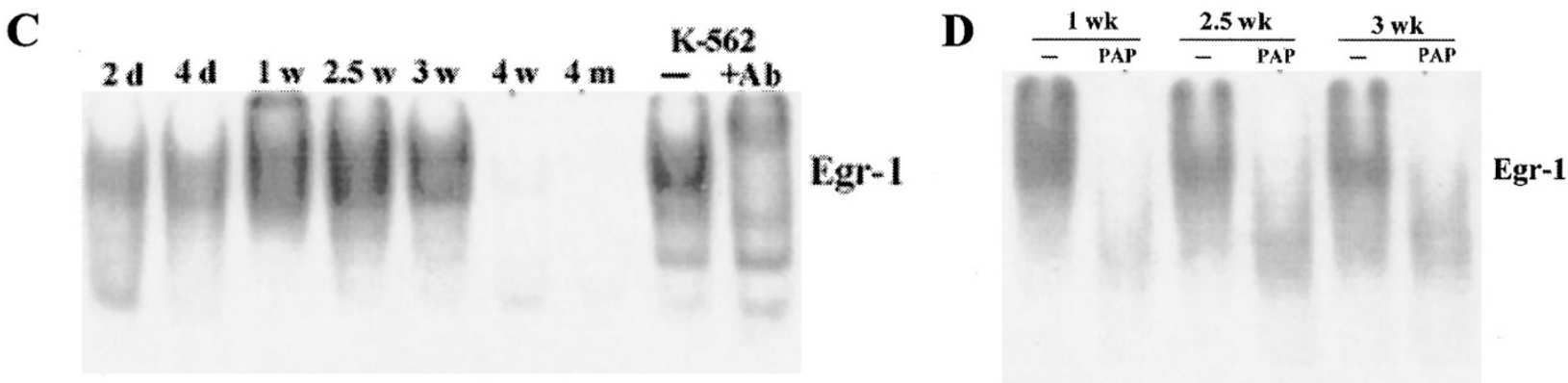

Figure 2. Egr-1 and GALK expression in mouse liver. $(A)$ Egr-1 and GALK mRNA developmental changes. Total RNA extracted from mouse livers at the indicated ages was analyzed by Northern blotting as described in "Materials and Methods." E18, embryonic d 18; Neo, postnatal d 1. GAPDH was used as an RNA loading control. Lanes $A$ and $B$ refer to RNA obtained from two different littermates. $(B)$ Developmental changes in Egr-1 protein. Western blotting was used to assess the Egr-1 content in liver nuclear extracts prepared from mice of the indicated ages. Equal amounts of protein ( $20 \mu \mathrm{g})$ were loaded in each lane and the blot was probed with Egr-1 antiserum obtained from Jeff Milbrandt. (C) Egr-1 binding activity. Electrophoretic mobility shift analysis of Egr-1 DNA binding activity was performed on nuclear extracts from mouse liver at the indicated ages. Extract from the phorbol ester-treated human cell line K-562 was used as a positive control. Super shift was performed using $1 \mu \mathrm{L}$ antibody against Egr-1. The probe sequence was GGATCCA(GCGGGGGCGA) ${ }_{2}$. $(D)$ Dependence of Egr-1 binding on phosphorylation. Extracts were treated with PAP before the addition of the labeled Egr-1 probe. Note the loss of binding activity in each of the extracts after PAP treatment.

absent at 4 wk or 4 mo. The ability of Egr- 1 to bind DNA is dependent on phosphorylation (19). To test whether phosphorylation was required for formation of the Egr-1 complexes, nuclear extracts were treated with PAP before addition of the DNA probe. PAP treatment completely eliminated Egr-1 complex formation in positive extracts (Fig. 2D).

The galactokinase promoter contains potential Egr-1 binding sites. To ascertain a role of Egr-1 in mouse liver during the sucking period, we searched for potential Egr-1 binding sites in the promoter regions of genes expressed specifically during this stage. One such gene was $G l k$, encoding galactokinase that performs the first covalent step in galactose utilization. The genomic sequence of the promoter region was obtained from Mus musculus chromosome 11 clone RP23-42F6 (GenBank Accession \# AL607108; see Fig. 3). Two pairs of Egr-1 recognition sequences were identified in the 150 nucleotides upstream of the ATG start codon. The distal and proximal pairs were separated by five and six nucleotides, respectively. Also indicated in Figure 3 are the potential binding sites for AP-4 and Nkx-2.5. As was reported for the human GALK1 gene (23), no obvious TATA box was present in the 5 '-flanking region. The potential TGTAA variant is indicated in bold and with a question mark.
Galactokinase mRNA expression pattern during suckling. Liver galactokinase activity is known to increase approximately 5-fold during neonatal life in the rodent (24). To determine whether galactokinase expression was regulated at the level of mRNA abundance, we examined its developmental expression pattern by reprobing the same Northern blot used for Egr-1. Galactokinase mRNA increased during the suckling period and diminished around the time of weaning (Fig. 2A). This result suggests that the postnatal increase in galactokinase activity is due at least in part to transcriptional regulation. The similar expression profile of galactokinase and Egr-1 supports the proposal that Glk is an Egr-1 target gene. Note, however, that the galactokinase mRNA level declined before the Egr-1 mRNA level did.

Activity of the Glk promoter. To test the ability of the galactokinase gene promoter to stimulate transcription, different fragment lengths were obtained by PCR from mouse genomic DNA. Fragments of 425 bp, 272 bp, 155 bp, and 83 bp from the 5'-flanking region of the gene were cloned upstream of the firefly luciferase reporter gene in vector pGL3basic to yield the plasmids shown in Figure 4. These plasmids were transiently transfected into Hep3B cells, a human hepatoma cell line that expresses Egr-1 (25). Cell extracts were 
-500 GGCTCTCCTT GTTtATCCCT AgACTgmgtA CCACATCATC CTGTTAgAgA

-450 CATGACCGAC CAgGgGCtGA CGACtTAgCA TAACtTCGCT AgAtCCtCTg AP-4

-400 GGACA CTCAG CTGTTCCTGT TGCCAGCTCG TGTTGGTGT GCCCTGGCTG

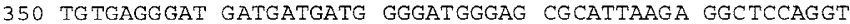

Nkx-2.5

-300 TCAGgGatgg AtgGgaAtT CAgAtCtCCA TTtgtgtTAA CTGCTACTCA

-250 AGTGGGAGCC CCAAACTCCT GCTAGGACAT CACCGAAGAT ACAAGTTGCA

-200 ACCGAgtCTC tTCCTCCAGC TGtCAgCtgC CGCGTTGGCT TGCGCtgGag Egr-1

-150 AgCTAAgTTT GGACCCCGCT CTGCAGGTGG GATGG GCGGG GCCGTCGTAG Egr-1

TATA box (?)

-100 CGGGGGCGGg GTCCCGCGAA GGACAgGAAT GTAAGTCCGC GCCACGTGGC Egr-1 Egr-1 $\downarrow$

50 TCCGCCCCCA GCATCCCGCG GGGCGGTGCG CCCAGCTGCA GACGAGCGTC

Start codon

1 ATGGCTGCTT GGAGACCGCC CCGGGTCGAG GAGCTGCTGG CCGAGGCCCG

Figure 3. Genomic sequence of the promoter region of mouse Galactokinase gene. The sequence was obtained from Mus musculus chromosome 11 clone RP23-42F6. The numbering assigns +1 to the ATG translation initiation codon (underlined), consistent with the human GALK1 gene (23). Potential binding sites for transcription factors are indicated by boxes in boldface type. The vertical arrow indicates the site corresponding to the transcription initiation site in the human gene.

assayed for relative luciferase activity $48-72 \mathrm{~h}$ after transfection. pGK $(-425)$ Luc directed transcription with activity 4-fold higher compared with the promoterless pGL3 (Fig. 4). Maximal transcriptional activity was observed with pGK $(-155)$ Luc, the shortest fragment that encompassed both pairs of potential Egr-1 binding sites. This construct had more than twice the activity of pGK $(-83)$ Luc. The activity of pGK $(-272)$ Luc was not significantly different from pGK( -425$)$ Luc (Fig. 4). The pGK(-83)Luc construct, which contains only one pair of putative Egr-1 binding sites, had transcriptional activity comparable to that found for pGK $(-425)$ Luc and pGK $(-272)$ Luc. From these data, we surmised that Egr-1 plays an active role in regulating galactokinase gene transcription. In addition, an inhibitory site appears to be present at or near the Nkx-2.5 element.

To provide further evidence for a role for Egr-1 in galactokinase gene transcription, we tested the effect of overexpressing Egr-1 in hepatoma cell lines $\mathrm{Hep} 3 \mathrm{~B}, \mathrm{HuH} 7$, and HepG2. Preconfluent cells were transfected with pGK $(-425)$ Luc and with or without the expression construct pCMV-Egr-1. Compared with single transfection, cotransfection of Hep3B yielded $41 \pm 45 \%(n=3)$ more relative luciferase activity (Fig. 5). In the other cell lines, luciferase activity increased $26 \pm 31 \%(n=3)$ in HepG2 and $39 \pm 18 \%$ $(n=3)$ in $\mathrm{HuH} 7$ with Egr-1 expression vector compared with without (Fig. 5). In eight of the nine transient transfection experiments performed, Egr-1 cotransfection led to increased luciferase reporter activity, which was statistically significant in three experiments with $\mathrm{HuH7}$ ( $p=0.026$ by one-tailed $t$ test). These data suggest that Egr-1 expression can activate the galactokinase promoter in cell culture. However, because HepG2 and $\mathrm{HuH} 7$ also express the Egr-1 protein (26), the dependence on co-transfected Egr-1 was not absolute in any of the cell lines.

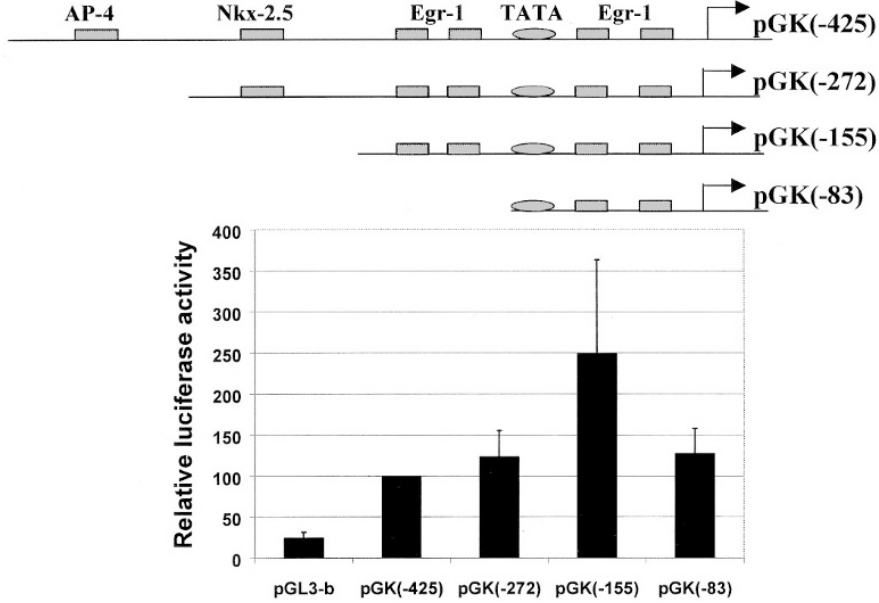

Figure 4. GALK promoter activity in Hep3B cells. The upper panel shows a schematic representation of the GALK promoter fragments cloned upstream of firefly luciferase in the pGL3-basic reporter plasmid. The numbers in plasmid names refer to the extent of the galactokinase promoter sequence upstream of the ATG start codon. The lower panel shows the relative luciferase activity in Hep3B cells transfected with promoter-reporter plasmids. Preconfluent Hep3B cells were transfected either with pGL3-basic (pGL3-b) as a baseline control or with GALK promoter/luciferase reporter constructs pGK $(-425) \mathrm{Luc}$, pGK(-272)Luc, pGK $(-155)$ Luc, or pGK $(-83)$ Luc. Firefly luciferase activities were normalized to co-transfected Renilla luciferase using the pRL-TK plasmid. The activities of all constructs were significantly different from that of the promoterless pGL3-b plasmid $(p<0.01)$ and the activity of pGK $(-155)$ Luc was significantly different from that of $\mathrm{pGK}(-425)$ Luc $(p<$ $0.02)$.

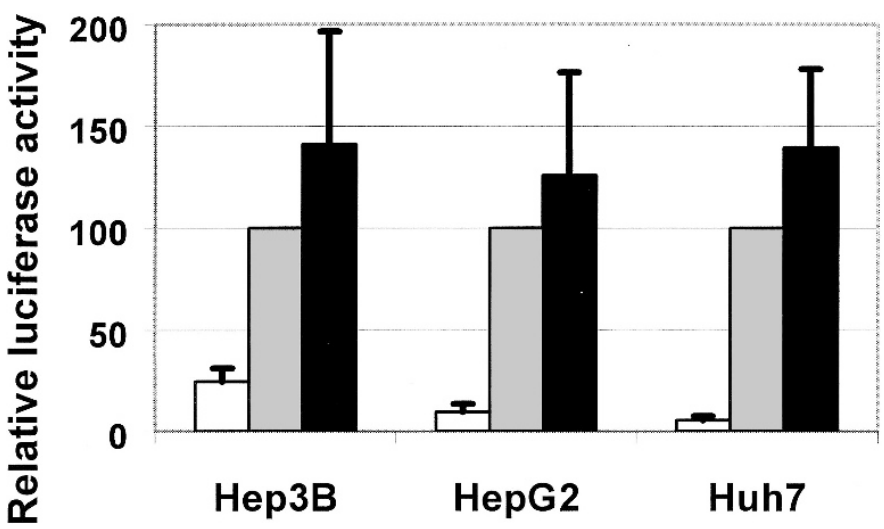

Figure 5. Activation of the GALK promoter by Egr-1 in hepatoma cell lines. Preconfluent Hep3B, HepG2, or HuH7 cells were transfected with the reporter construct pGK( $(-425)$ Luc with (filled bars) or without (cross-hatched bars) the Egr-1 expression plasmid CMV-Egr-1. Background activity was assessed using the pGL3-basic plasmid (pGL3-B, open bars). Firefly luciferase activities were normalized to co-transfected Renilla luciferase using the pRL-TK plasmid.

Mutational analysis of the Glk promoter. To assess the role of the Egr-1 binding sites, we introduced mutations into either or both sites in each pair (indicated by bold face type in Table 1). The distal pair sites were mutated in pGK $(-155)$ Luc and the proximal pair sites were mutated in pGK $(-83)$ Luc. Schematics of these constructs are shown in Figure 6. These plasmids were transiently transfected into Hep3B cells and cell extracts were prepared $48-72 \mathrm{~h}$ later to assay relative luciferase activity. pGK $(-155) \mathrm{mA}$ reduced the luciferase activity approximately $40 \%$, pGK $(-155) \mathrm{mB}$ approximately $55 \%$, and 

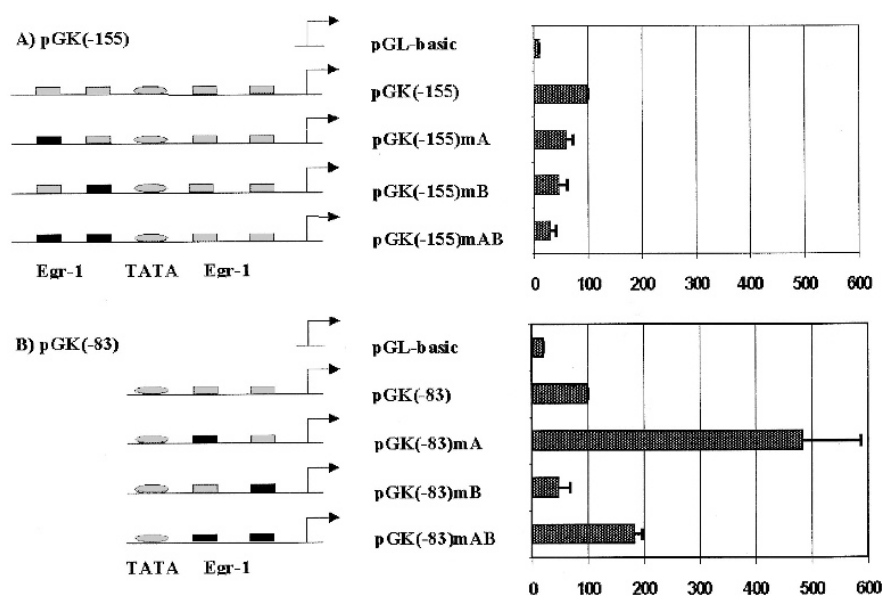

Figure 6. Mutational analysis of the GALK Egr-1 sites. Reporter plasmids were prepared in which either one of both of a pair of adjacent Egr-1 sites were mutagenized. The mutant sequences are shown in Table 1. See "Materials and Methods" for details. Each panel shows a schematic representation of the reporter plasmids with the mutant site depicted in black. Transient transfection and analysis were performed as described in Figure 4. (A) Analysis of the distal Egr-1 sites in pGK $(-155)$. (B) Analysis of the proximal Egr-1 sites in pGK $(-83)$.

the double mutant approximately $70 \%$ compared with wildtype pGK(-155)Luc (Fig. 6A). Remarkably, mutation of the first Egr-1 motif in pGK $(-83) \mathrm{mA}$, the shorter promoter, led to an increase of promoter activity about 5 -fold over that of the wild type (Fig. 6B). However, mutation of the second Egr-1 motif in the pGK $(-83) \mathrm{mA}$ yielded only $46 \%$ of the luciferase activity found in the wild-type pGK $(-83)$ Luc (Fig. $6 B)$. The double mutant was $80 \%$ more active than the wild type and approximately 4-fold more active than the $\mathrm{pGK}(-83) \mathrm{mB}$ single mutant (Fig. 6B), suggesting that each of these two motifs acts independently in controlling promoter activity. It is interesting to note that in side-by-side assays, the pGK $(-83) \mathrm{Luc}$ construct was consistently twice as active as the pGK $(-155) \mathrm{mAB}$ construct $(2.1 \pm 0.22, p=0.013 ; n=3)$. This result suggests that an undefined repressor element may be present between -155 and -83 in the Glk promoter. Analysis of the mutant DNA sequences using the Mapplot program (Accelrys, San Diego, CA, U.S.A.) did not reveal any newly created transcription factor binding sites.

Galactokinase expression in Egr-1 null mice. To test whether Egr-1 expression is essential for GalK induction during suckling, we prepared Northern blots with RNA extracted from livers of Egr-1 null mice. As can be seen in Figure 7,

Table 1. Distal and proximal Egr-1 binding sites Distal Egr-1 binding sites $(-119$ to -89$)$

Wild type $\quad$ ATGG GCGGGGCCG TCGTA GCGGGGGCG GGGT $\begin{array}{ll}\text { GK }(-155) \mathrm{mA} & \text { ATGG GCGGGTTAG TCGTA GCGGGGGCG GGGT } \\ \text { GK( }(-155) \mathrm{mB} & \text { ATGG GCGGGGCCG TCGTA GCGGGTTTG GGGT }\end{array}$ GK(-155)mAB ATGG GCGGGTTAG TCGTA GCGGGTTTG GGGT

\begin{tabular}{ll}
\hline & Proximal Egr-1 binding sites $(-52$ to -21$)$ \\
\hline Wild type & GCTC CGCCCCCAG CATCCC GCGGGGCGG TGCG \\
GK $(-83) \mathrm{mA}$ & GCTC CTTACCCAG CATCCC GCGGGGCGG TGCG \\
GK $(-83) \mathrm{mB}$ & GCTC CGCCCCCAG CATCCC GTTTGGCGG TGCG \\
GK $(-83) \mathrm{mAB}$ & GCTC CTTACCCAG CATCCC GTTTGGCGG TGCG \\
\hline
\end{tabular}

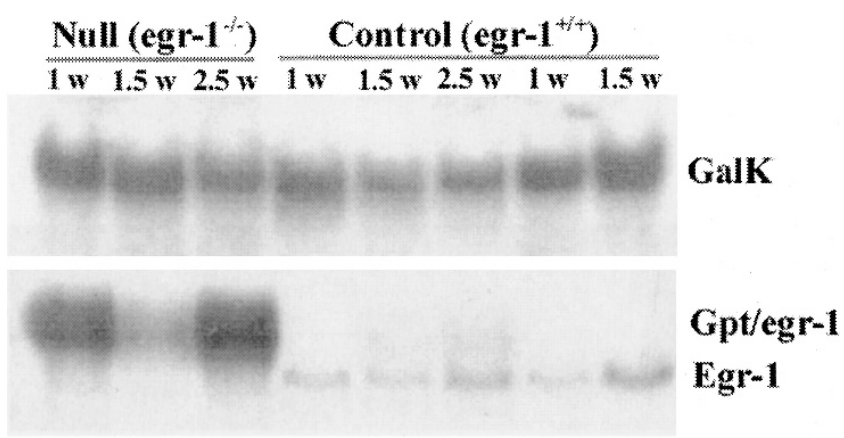

Figure 7. Egr-1 and GALK expression in Egr-1 null mouse liver. Total RNA extracted from mouse livers at the indicated ages was analyzed by Northern blotting as described in Materials and Methods. The signals obtained following hybridization with the GalK probe are shown in the upper panel and with the Egr-1 probe in the lower panel.

upper panel, the abundance of GalK mRNA in Egr-1 null mice was comparable to that found in wild-type littermates at the three suckling ages examined. Thus, GalK expression does not exhibit an absolute dependence on Egr-1 in vivo. RT-PCR was performed to test whether the loss of Egr-1 expression led to a compensatory increase in the expression of another Egr family member. Egr-2 was detected in one time point of each genotype. However, because the signals occurred at different times, it is unlikely due to compensatory expression. Egr-3 was detected in all the samples, but its expression was weak and similar between the Egr-1 ${ }^{+/+}$and liver Egr-1 ${ }^{-/-}$samples (data not shown). Egr-4 was not detected in any liver sample, but was readily detectable in brain cortex. Whether posttranscriptional changes occurred in Egr-3 activity was not tested.

When the blot was stripped and re-probed to confirm the absence of Egr-1 mRNA in null mice (Fig. 7, lower panel), a new, very strong Egr-1 hybridizing transcript appeared (Fig. 7; Gpt/Egr-1). Because this transcript also hybridized to a Gpt cDNA probe (not shown), it is likely that this mRNA was transcribed from the disrupted Egr-1 allele in which the bacterial neomycin resistance gene replaced Exon 2 (27). Whether this transcript arose from the endogenous Egr-1 promoter or from the promoter fused to the Gpt neomycin resistance gene was not tested.

\section{DISCUSSION}

Egr-1 has been most thoroughly studied in neural, endothelial, and hematopoietic tissues (28-30). In many cases, attention has been focused on its involvement in acute responses, particularly to stress. However, the high expression of Egr-1 in the adult brain (31) as well as its basal expression in several other tissues $(32,33)$ indicates that Egr-1 also functions in nonacute processes. Our finding that Egr-1 is developmentally regulated in liver provides evidence for its involvement in the transition of hepatocytes from fetal to adult character during the neonatal period.

While seeking candidate target genes for Egr-1, we found putative Egr-1 enhancer elements in the GALK gene promoter. GALK is the first enzyme in the Leloir pathway in the conversion of galactose to glucose (34). GALK deficiency (MIM230200) has been associated with cataracts (e.g. see ref. 
35) and dysregulation of GALK in type 1 neurofibromatosis has been associated with abnormalities of germ cell and neural crest development (36). Studies have demonstrated age-related changes in GALK expression with both human children (37) and neonatal rats (24) exhibiting higher activities than adults. Our studies show that, at least in mice, this regulation occurs at the level of mRNA abundance.

Our results tie Egr-1 and GALK together in a developmentally regulated chain controlling the change in metabolic pathways. To summarize, we found that i) Egr-1 exhibits a surge in expression during the suckling period in mice; ii) GALK exhibits a concomitant surge at the mRNA level; iii) the Glk promoter contains response elements that recognize and respond to Egr-1 in transient transfection assays; and, finally, iv) mutating three of the four sites reduced Egr-1 responsiveness, whereas the fourth appeared to exert negative influence over the Glk promoter.

A modest amount of information is available regarding the function of Egr-1 in supporting the expression of genes encoding enzymes of intermediary metabolism. One case is the involvement of Egr-1 in the insulin responsiveness of the gene for cytosolic malic enzyme (12). Treatment of hepatoma cells with insulin greatly increased binding of Egr-1, identified by antibody super-shifting, to an Egr-1 motif overlapping one of the insulin response sequences. However, although mutating the Egr-1 site prevented the element from competing for binding, the activity of the mutated site was not examined by transfection analysis. Subsequently, it was shown that Egr-1 repressed malic enzyme expression by displacing SP1 from overlapping sites in the gene promoter (38). Egr-1 expression itself is affected by nutritional status. Systemic ghrelin administration increases the number of Egr-1 positive cells in the arcuate nucleus, particularly in fasted rats, indicating that Egr-1 may play a role in mediating responses to food intake (13). At the cellular level, certain cell types induce Egr-1 when exposed to high glucose concentrations. In mesangial cells, this induction has been shown to be brought about by an autocrine transforming growth factor- $\beta$ loop (39). Also of interest is the induction of Egr-1 by pancreatic $\beta$ cells in response to high glucose $(11,40)$. The former authors traced the induction to the activation of serum response factor by glucose-induced depolarization. Glucose-induced Egr-1 expression does not appear to be a general phenomenon because it did not occur in either fibroblasts or hepatocytes (39).

The co-regulation of galactokinase with Egr-1 along with the presence of Egr-1 sites in the mouse gene promoter led us to analyze the dependence of galactokinase gene expression on Egr-1 further. All four of the Egr-1 motifs found were present in the 115 nucleotides upstream of the ATG translation start codon. However, the Egr-1 binding sites did not contribute equally to Glk promoter activity in transient transfection analyses performed in cell cultures. The distal pair and the second proximal site appeared to act as enhancer elements, whereas the first proximal site appeared to act as a repressor element. As noted above, repression by Egr-1 via competition for SP-1 binding has been documented in several studies $(41,42)$. However, canonical SP1 sites overlap both of the distal Egr-1 motifs, both of which contributed positively to Glk promoter activity, but neither of the proximal sites. Finally, we noted that galactokinase mRNA levels declined postnatally earlier than those for Egr-1. Whether the galactokinase down-regulation occurred through the apparent Egr-1 repressor element or by a different mechanism is not known at this time.

Comparison of the human and mouse Glk promoters revealed similarities: both are GC-rich-the proximal 200 base pairs of the human Glk $5^{\prime}$ flank is $69 \% \mathrm{G}+\mathrm{C}$ whereas that in mouse is $70 \% \mathrm{G}+\mathrm{C}$ - and neither has a canonical TATAA sequence or CAAT box. However, none of the Egr-1 motifs identified in mouse sequence are present in the human Glk promoter. Whether the human promoter is still Egr-1responsive via noncanonical Egr-1 sites or the role of Egr-1 is taken over by a different transcription factor will have to await further studies.

Despite our evidence that galactokinase expression is dependent on Egr-1 in transient transfection experiments, Glk gene expression exhibited a normal postnatal surge in Egr-1 null mice. Because all Egr family members bind to same enhancer elements (28), it is possible that a redundant pathway is present or a compensatory induction of other family members occurs in the Egr-1 null mice. Egr-1 null mice, with the exception of female infertility, exhibit normal growth and development (43). These authors noted that many processes normally associated with Egr-1 in cell cultures do not show the same dependence in vivo. Resolution of this question will require further studies.

In summary, we have provided evidence for a dependence of galactokinase expression on Egr-1 in the mouse. Additional studies will be required to detail its developmental expression pattern in human liver as well as to assess the regulation of galactokinase in humans. Also, it will be of interest to ascertain the specific factors that lead to the postnatal surge of Egr-1 expression in the liver and to identify other hepatic targets and metabolic pathways regulated by this gene.

Acknowledgments. The authors thank Dr. Jeffrey Milbrandt (Washington University School of Medicine, St. Louis, MO) for providing Egr-1 null mice and Egr-1 antiserum, Dr. Daniel A. Haber (MGH Cancer Center) for providing the mouse Egr-1 cDNA, Dr. Ernestina Schipani for paraffin embedding and sections, Dr. Urs Berger for the immunostaining, and Lihua Zhang for expert technical assistance.

\section{REFERENCES}

1. Lau LF, Nathans D 1987 Expression of a set of growth-related immediate early genes in BALB/c 3T3 cells: coordinate regulation with c-fos or c-myc. Proc Natl Acad Sci U S A 84:1182-1186

2. Milbrandt J 1987 A nerve growth factor-induced gene encodes a possible transcriptional regulatory factor. Science 238:797-799

3. Lim RW, Varnum BC, Herschman HR 1987 Cloning of tetradecanoyl phorbol ester-induced 'primary response' sequences and their expression in density-arrested Swiss 3 T3 cells and a TPA non-proliferative variant. Oncogene 1:263-270

4. Sukhatme VP, Cao XM, Chang LC, Tsai-Morris CH, Stamenkovich D, Ferreira PC, Cohen DR, Edwards SA, Shows TB, Curran T, et al 1988 A zinc finger-encoding gene coregulated with c-fos during growth and differentiation, and after cellular depolarization. Cell 53:37-43

5. Lemaire P, Revelant O, Bravo R, Charnay P 1988 Two mouse genes encoding potential transcription factors with identical DNA-binding domains are activated by growth factors in cultured cells. Proc Natl Acad Sci U S A 85:4691-4695

6. Christy BA, Lau LF, Nathans D 1988 A gene activated in mouse 3 T3 cells by serum growth factors encodes a protein with "zinc finger" sequences. Proc Natl Acad Sci U S A 85:7857-7861 
7. Gashler A, Sukhatme VP 1995 Early growth response protein 1 (Egr-1): prototype of a zinc-finger family of transcription factors. Prog Nucleic Acid Res Mol Biol 50:191-224

8. Mages HW, Stamminger T, Rilke O, Bravo R, Kroczek RA 1993 Expression of PILOT, a putative transcription factor, requires two signals and is cyclosporin A sensitive in T cells. Int Immunol 5:63-70

9. Mohn KL, Laz TM, Hsu JC, Melby AE, Bravo R, Taub R 1991 The immediate-early growth response in regenerating liver and insulin-stimulated H-35 cells: comparison with serum-stimulated 3T3 cells and identification of 41 novel immediate-early genes. Mol Cell Biol 11:381-390

10. Das A, Chendil D, Dey S, Mohiuddin M, Milbrandt J, Rangnekar VM, Ahmed MM 2001 Ionizing radiation down-regulates p53 protein in primary Egr-1-/- mouse embryonic fibroblast cells causing enhanced resistance to apoptosis. J Biol Chem 276:3279-3286

11. Josefsen K, Sorensen LR, Buschard K, Birkenbach M 1999 Glucose induces early growth response gene (Egr-1) expression in pancreatic beta cells. Diabetologia 42:195-203

12. Streeper RS, Chapman SC, Ayala JE, Svitek CA, Goldman JK, Cave A, O'Brien RM 1998 A phorbol ester-insensitive AP-1 motif mediates the stimulatory effect of insulin on rat malic enzyme gene transcription. Mol Endocrinol 12:1778-1791

13. Hewson AK, Dickson SL 2000 Systemic administration of ghrelin induces Fos and Egr-1 proteins in the hypothalamic arcuate nucleus of fasted and fed rats. J Neuroendocrinol 12:1047-1049

14. Cao XM, Koski RA, Gashler A, McKiernan M, Morris CF, Gaffney R, Hay RV, Sukhatme VP 1990 Identification and characterization of the Egr-1 gene product, DNA- binding zinc finger protein induced by differentiation and growth signals. Mol Cell Biol 10:1931-1939

15. Gashler AL, Swaminathan S, Sukhatme VP 1993 A novel repression module, an extensive activation domain, and a bipartite nuclear localization signal defined in the immediate-early transcription factor Egr-1. Mol Cell Biol 13:4556-4571

16. Russo MW, Matheny C, Milbrandt J 1993 Transcriptional activity of the zinc finge protein NGFI-A is influenced by its interaction with a cellular factor. Mol Cell Biol 13:6858-6865

17. Molnar G, Crozat A, Pardee AB 1994 The immediate-early gene Egr-1 regulates the activity of the thymidine kinase promoter at the G0-to-G1 transition of the cell cycle. Mol Cell Biol 14:5242-5248

18. Swirnoff AH, Milbrandt J 1995 DNA-binding specificity of NGFI-A and related zinc finger transcription factors. Mol Cell Biol 15:2275-2287

19. Peng Y, Du K, Ramirez S, Diamond RH, Taub R 1999 Mitogenic up-regulation of the PRL-1 protein-tyrosine phosphatase gene by Egr-1. Egr-1 activation is an early even in liver regeneration. J Biol Chem 274:4513-4520

20. Tsai JC, Liu L, Cooley BC, DiChiara MR, Topper JN, Aird WC 2000 The Egr-1 promoter contains information for constitutive and inducible expression in transgenic mice. FASEB J 14:1870-1872

21. Rhoads DB, Rosenbaum DH, Unsal H, Isselbacher KJ, Levitsky LL 1998 Circadian periodicity of intestinal $\mathrm{Na}+$ /glucose cotransporter 1 mRNA levels is transcriptionally regulated. J Biol Chem 273:9510-9516

22. Wen P, Locker J 1994 A novel hepatocytic transcription factor that binds the alphafetoprotein promoter-linked coupling element. Mol Cell Biol 14:6616-6626

23. Bergsma DJ, Ai Y, Skach WR, Nesburn K, Anoia E, Van Horn S, Stambolian D 1996 Fine structure of the human galactokinase GALK1 gene. Genome Res 6:980-985

24. Rogers SR, Bovee BW, Saunders SL, Segal S 1989 Activity of hepatic galactosemetabolizing enzymes in the pregnant rat and fetus. Pediatr Res 25:161-166
25. Lin YL, Chen HC, Yeh SF, Chou CK 1995 Differential pathways of insulin action upon the hepatitis B surface antigen gene expression and cell proliferation in human hepatoma cells. Endocrinology 136:2922-2927

26. Kawashita Y, Ohtsuru A, Kaneda Y, Nagayama Y, Kawazoe Y, Eguchi S, Kuroda H, Fujioka H, Ito M, Kanematsu T, Yamashita S 1999 Regression of hepatocellular carcinoma in vitro and in vivo by radiosensitizing suicide gene therapy under the inducible and spatial control of radiation. Hum Gene Ther 10:1509-1519

27. Lee SL, Sadovsky Y, Swirnoff AH, Polish JA, Goda P, Gavrilina G, Milbrandt J 1996 Luteinizing hormone deficiency and female infertility in mice lacking the transcription factor NGFI-A (Egr-1). Science 273:1219-1221

28. Beckmann AM, Wilce PA 1997 Egr transcription factors in the nervous system. Neurochem Int 31:477-510

29. Khachigian LM, Collins T 1998 Early growth response factor 1: a pleiotropic mediator of inducible gene expression. J Mol Med 76:613-616

30. McMahon SB, Monroe JG 1996 The role of early growth response gene 1 (egr-1) in regulation of the immune response. J Leukoc Biol 60:159-166

31. O'Donovan KJ, Tourtellotte WG, Millbrandt J, Baraban JM 1999 The EGR family of transcription-regulatory factors: progress at the interface of molecular and systems neuroscience. Trends Neurosci 22:167-173

32. Watson MA, Milbrandt J 1990 Expression of the nerve growth factor-regulated NGFI-A and NGFI-B genes in the developing rat. Development 110:173-183

33. McMahon AP, Champion JE, McMahon JA, Sukhatme VP 1990 Developmental expression of the putative transcription factor Egr-1 suggests that Egr-1 and c-fos are coregulated in some tissues. Development 108:281-287

34. Frey PA 1996 The Leloir pathway: a mechanistic imperative for three enzymes to change the stereochemical configuration of a single carbon in galactose. FASEB J $10: 461-470$

35. Okano Y, Asada M, Fujimoto A, Ohtake A, Murayama K, Hsiao KJ, Choeh K, Yang Y, Cao Q, Reichardt JK, Niihira S, Imamura T, Yamano T 2001 A genetic factor for age-related cataract: identification and characterization of a novel galactokinase variant, "Osaka," in Asians. Am J Hum Genet 68:1036-1042

36. Cramer DW, Korf BR, Fortier LJ 1991 Galactose metabolism and reproductive history in women with type 1 neurofibromatosis. Am J Med Genet 39:502-508

37. Ng WG, Donnell GN, Bergren WR 1965 Galactokinase activity in human erythrocytes of individuals at different ages. J Lab Clin Med 66:115-121

38. Barroso I, Santisteban P 1999 Insulin-induced early growth response gene (Egr-1) mediates a short term repression of rat malic enzyme gene transcription. J Biol Chem 274:17997-18004

39. Wolf G, Sharma K, Chen Y, Ericksen M, Ziyadeh FN 1992 High glucose-induced proliferation in mesangial cells is reversed by autocrine TGF-beta. Kidney In 42:647-656

40. Bernal-Mizrachi E, Wice B, Inoue H, Permutt MA 2000 Activation of serum response factor in the depolarization induction of Egr-1 transcription in pancreatic islet beta-cells. J Biol Chem 275:25681-25689

41. Ackerman SL, Minden AG, Williams GT, Bobonis C, Yeung CY 1991 Functional significance of an overlapping consensus binding motif for Sp1 and Zif268 in the murine adenosine deaminase gene promoter. Proc Natl Acad Sci U S A 88:7523-7527

42. Huang RP, Fan Y, Ni Z, Mercola D, Adamson ED 1997 Reciprocal modulation between Sp1 and Egr-1. J Cell Biochem 66:489-499

43. Lee SL, Tourtellotte LC, Wesselschmidt RL, Milbrandt J 1995 Growth and differentiation proceeds normally in cells deficient in the immediate early gene NGFI-A J Biol Chem 270:9971-9977 